Estudios sobre armas antiguas, arte militar y vida cultural en oriente y occidente XXXII (2012), pp. 49-68

ISSN : 0436-029X

doi: 10.3989/gladius.2012.0003

\title{
EL PUGIO: NUEVOS DATOS PARA EL ESTUDIO DE SU ORIGEN ${ }^{1}$
}

\author{
THE ROMAN PUGIO: NEW DATA ON ITS ORIGIN
}

POR

Roberto De Pablo Martínez*

\section{RESUMEN - ABSTRACT}

Hace ya varias décadas que se aceptó la relación entre el puñal bidiscoidal (también llamado biglobular o dobleglobular) y el pugio, siendo este último deudor, en algunos de sus elementos más característicos, de la daga celtibérica. Sin embargo, hay partes del puñal romano que han quedado sin explicarse, desconociéndose cual pudiera ser su origen y de que arma las cogió prestadas. Este trabajo se centra fundamentalmente en demostrar la filiación entre el pugio romano y el, recientemente definido, puñal de «filos curvos» (antes llamado tipo La Osera o Villanueva de Teba); arma del que fueron tomados aquellos elementos que, carentes en el puñal bidiscoidal, están en el pugio.

Several decades ago the relationship between the «bidiscoidal» type dagger (also known as «biglobular» or «doblegobular») and the Roman pugio, was generally accepted, the Celtiberian dagger being the origin of many of its most characteristic elements. However, some elements of the Roman dagger have been left without explanation, their origin unknown. This paper provides data to show the relationship between the pugio and the so called «waisted type» dagger, recently defined (formerly described as «La Osera» type or «Villanueva de Teba» type). This weapon contains those elements that are lacking in the Celtiberian bidiscoidal dagger, but are present in the pugio, which can then be considered an hybrid form.

\section{Palabras Clave - Keywords}

Pugio; Puñal de filos curvos; Puñal bidiscoidal; Ejército romano; Duero.

Pugio; ‘waisted blade’ dagger; Dagger; Bidiscoidal dagger; Roman Army; Duero.

A Mángeles Miguel Con el mismo cariño con que guiaste mis primeros pasos.

Pugio, quem curva signatbrevis orbita vena. Stridenten gelidis hunc Salo tinxit aquis. Marcial (Libro VI, Epigrama XXXIII)

Marcial, a partir de este enigmático epigrama, es el único de los autores grecolatinos que nos insinúa mínimamente las raíces del puñal romano, puesto que la práctica totalidad de los

* Departamento de Prehistoria, Arqueología, Antropología Social y Ciencias y Técnicas Historiográficas. Facultad de Filosofía y Letras. Universidad de Valladolid. Correo electrónico: rdpablo@fyl.uva.es.

${ }^{1}$ Este trabajo se ha llevado a cabo en el marco del Proyecto de Investigación Cosmovisión y simbología vacceas. Nuevas perspectivas de análisis (HAR2010-21745-C03-01), de la Dirección General de Investigación del Ministerio de Ciencia e Innovación 
autores clásicos, al contrario de lo que ocurre con el gladius hispaniensis (Quesada, 1997b: 42-44; 2007: 391-398), nunca llegaron a incurrir en el origen del puñal legionario, y mucho menos en que sus raíces estuvieran en suelo ibérico. Sin embargo, la realidad arqueológica permitió, hace ya casi un siglo, plantear a Sandars (1913: 64) y después a Schulten (19141931: 214-215) su origen peninsular, aludiendo a la singular morfología que compartían las empuñaduras del pugio y de un arma indígena de la Meseta: el puñal bidiscoidal. En esta misma línea, en cuanto a la génesis del puñal, se moverían los trabajos posteriores de Schüle (1969: 106), Cabré de Morán (1990: 221-222), Feugère (1994: 163), Connolly (1997: 56), (1997b: 300 y 302), Filloy y Gil (1997: 138) o Bishop y Coulston (2006: 56-57), en los que el pugio tenía un mayor o único protagonismo. En estos estudios se aceptaba siempre el origen hispano del arma romana, aunque con importantes matizaciones acerca de la forma de la hoja, ya que Sandars desconocía puñales bidiscoidales con hojas pistiliformes, o sobre el modo de adquisición. Teoría esta que se muestra en consonancia con las fuentes literarias clásicas, las cuales constatan un profundo contacto entre romanos y celtiberos desde la Segunda Guerra Púnica, pasando por las Guerras Celtibéricas, hasta la conquista total de la Celtiberia a principios del siglo I a.C. e incluso cuando Roma utilizó tropas auxiliares celtíberas.

Por lo tanto, podríamos decir que hoy día nadie duda sobre el origen hispano del pugio romano, es más, la investigación académica en su mayoría apunta, no sin razón, al Alto Duero como lugar de adquisición, y al puñal bidiscoidal como el origen de la pieza romana. No obstante, los problemas sobre sus raíces son patentes y la relación bidiscoidal-pugio no termina de cuajar; algo de lo que se han percatado ya varios autores (Quesada, 2006: 76-77 y 2007: 387391; Kavanagh, 2008: 66-69; Fernández Ibáñez, 2008: 111-115; Kavanagh y Quesada, 2009) y que ahora intentaremos abordar aportando nuevos datos y una perspectiva diferente.

El presente artículo no tiene como objetivo afianzar más la relación entre el puñal celtibérico y el romano, puesto que es una labor que creemos que en los últimos años han cumplido sobradamente los trabajos de Kavanagh (2008) y Fernández Ibáñez (2008). Sí, en cambio, la de introducir una nueva arma, el puñal de filos curvos (De Pablo, 2010), que creemos rellena aquellos vacíos que todavía hay en el proceso de formación del pugio. Por ello nuestra atención estará dirigida a confirmar la filiación entre el arma romana y el puñal de filos curvos, sin que ello haya de entenderse como un intento de desplazar a los bidiscoidales.

\section{EL PUÑAL CELTIBÉRICO Y EL PUGIO, UNA RELACIÓN NO TAN ESTRECHA}

El puñal bidiscoidal remonta su origen al siglo III a.C. y perdura entre las poblaciones celtibéricas hasta la conquista romana de la zona en los siglos II-I a.C. Esta arma, originaria de la Celtiberia, se extendió, aparte de en esa zona nuclear, a lo largo del Sistema Central llegando a formar parte, no solo de la panoplia de las poblaciones de celtiberas, sino también de las vettonas. Estos puñales presentan hojas con formas pistiliformes, triangulares y de filos paralelos, con unas dimensiones medias en torno a los 15/21 cm de longitud y los 4/5,5 cm de anchura máxima. Por su parte, la empuñadura es la parte más singular del arma, está construida sobre una lengüeta y formada, a su vez, por dos pletinas metálicas con dos discos dispuestos de manera vertical —uno en el pomo y otro en el puño-. Entre las pletinas y la lengüeta se colocarían dos cachas, normalmente orgánicas, unidas todas ellas por unos remaches de hierro. Finalmente, las vainas están compuestas por un armazón de cantoneras de hierro, unidas en la embocadura y en el centro por dos puentes y en la contera por un remate macizo. Para su suspensión, a uno de los dos lados de los puentes, se disponen anillas por las que pasaría un tahalí de cuero. 
Por lo tanto, a tenor de los rasgos propios de los puñales celtibéricos y teniendo en cuenta las características de los pugiones altoimperiales del limes germánico, la relación entre ambos es obvia. Esta relación, como anteriormente señalábamos, reside en su innegable parecido externo, tanto en la hoja como, sobre todo, en la empuñadura. Además, si a los indudables parecidos tipológicos sumamos que el bidiscoidal era un arma propia de las gentes de la Celtiberia al menos desde el siglo III a.C. y que el ejército romano durante las Guerras Celtibéricas entraría en contacto con esta daga ${ }^{2}$, se situaría el puñal celtibérico en un lugar inmejorable como pieza base en la formación del pugio.

Sin embargo, una vez que desmontamos el puñal romano y nos adentramos en las características de la propia daga, de la vaina y de la suspensión, observamos importantes diferencias entre uno y otro. Y es que, desde la adopción del puñal bidiscoidal por algunos soldados romanos en la Celtiberia durante el siglo II a.C. a modo de trofeo o botín ${ }^{3}$, hasta la aparición del pugio en época augustea como parte del armamento reglamentario del ejército romano, hay un lapso de cien años. Esta centuria, en la que habría que centrarse para conocer ese supuesto proceso de evolución de un arma a la otra, que explicara además las divergencias tipológicas a las que aludíamos más arriba, a día de hoy se presenta como una laguna arqueológica.

Durante los últimos años son varios los trabajos (Quesada, 2007: 387-391; Kavanagh, 2008: 66-69; Kavanagh y Quesada, 2009) que han puesto sobre la mesa estas diferencias morfológicas y estructurales a las que venimos haciendo referencia. Estas son las siguientes:

- Aunque mantiene la morfología exterior de la empuñadura, ésta ya no solo se monta sobre una lengüeta sino también sobre una espiga de sección rectangular, tal como muestra uno de los puñales de Usk (Scott, 1985: 206, fig. 2, 65).

- Los hombros de la hoja, ahora, no solo se presentan caídos como en los modelos celtibéricos, sino que forman ángulo recto respecto al eje de la hoja, apareciendo rectos.

- Los pomos de algunos puñales están rematados por una o más virolas esféricas o hemisféricas, como vemos claramente en los puñales de Oberammergau, Mainz-Weisenau (Bishop y Coulston, 2006: pl. 1, fig. 42.4), Allériot (Bonnamour y Fernoux, 1969: figs. 1 y 4) o Velsen (Morel y Bosman, 1989: figs. 7 y 9A).

- Se generalizan los pomos en forma de D invertida o semicírculo, muchas veces decorados mediante nielados de plata.

- Las hojas en los pugiones son casi exclusivamente pistiliformes, mientras que los ejemplares celtibéricos presentan también hojas triangulares y de filos paralelos (Kavanagh, 2008: 50-52) .

- Algunas hojas presentan acanaladuras en su superficie, ausentes en los puñales celtibéricos, caso del puñal de Leeuwen (Ypey, 1960-1961: fig. 12) o Nijmegen (Bogaers y Ypey, 1962-1963: fig. 9).

- El tamaño de las hojas crece, la mayoría de los pugiones tienen más de veinte centímetros.

2 El contacto entre soldados romanos y el arma celtibérica esta constatada desde mediados del siglo II a.C. por la aparición de puñales bidiscoidales en los campamentos del cerco numantino de Castillejo en Garray y La Atalaya de Renieblas (Kavanagh, 2008: 75).

3 Coincidimos con Quesada (2007: 391) en que dicha arma fue adoptada en la guerra numantina de manera individual, por algunos soldados y oficiales, a modo de botín de guerra o trofeo. Sin que ello haya de entenderse como una inclusión entre las armas reglamentarias romanas.

4 No hacemos mención a su tipo «de base dilatada» por no ver suficientes diferencias con la forma pistiliforme, por las que se pueda hablar de un tipo diferente. 
- La vaina construida anteriormente por cantoneras en los laterales y unos puentes de hierro que las unían, pasa a estar constituida por dos grandes láminas o placas decoradas que cubren toda la superficie de la hoja con un cuerpo de madera o, en menor medida, de cantoneras de hierro como el caso de Allériot (Bonnamour y Fernoux, 1969: figs. 1 y 4$)$.

- La funda se remata en la contera por un disco hueco, inexistente en los ejemplares celtibéricos.

- La vaina presenta cuatro y no dos anillas de suspensión como en los bidiscoidales.

- El puñal no va colgado mediante un tahalí de cuero, sino que queda suspendido por dos pequeños tahalíes metálicos articulados en el lado izquierdo de la cadera, tal y como reflejan las estelas de los legionarios y auxiliares Flavoleius Cordus, Petilius Secundus, Firmus y Annaius Daverzus (Bishop y Coulston, 2006: fig. 150) en el limes germánico.

- Las vainas de los pugiones ofrecen una rica decoración de damasquinados; decoración escasa en las fundas de los ejemplares celtibéricos.

A la vista de las importantes diferencias tipológicas entre un modelo y otro, las cuales van más allá del mero aspecto externo, deberíamos preguntarnos ¿qué ocurrió durante ese siglo I a.C.? Hasta la actualidad los documentos arqueológicos que se han venido utilizando para explicar este hiato se han mostrado insuficientes, caso del puñal de Alesia (Luik, 2002: 88, fig. 52, 6), la estela del centurión Minucius Lorarius en Padua (Bishop y Coulston, 2006: fig. 22), el puñal de Titelberg (Vanden Berghe y Simkins, 2001), la vaina de Basel (Helmig, 1990) o la moneda de Marco Junio Bruto conmemorativa del asesinato de Julio César (Kavanagh, 2008: 79, fig. 23). Por ello deberíamos buscar, ya no ejemplos poco explícitos que resuelvan esta incógnita, sino un tipo de puñal que posea la mayoría de los elementos que, carentes en los bidiscoidales, se encuentren en los pugiones altoimperiales. Es decir, una pieza que actúe como la llave que permita resolver esta incógnita. Bajo nuestro punto de vista, esa variable ignorada hasta el momento y que aporta la clave para comprender el origen del puñal romano es el puñal de filos curvos (De Pablo, 2010), sobre el que volveremos a continuación con mayor detenimiento.

Por ello, y bajo nuestro punto de vista, la lectura que ha imperado hasta el momento sobre el origen del pugio, basada únicamente en el puñal bidiscoidal, se presenta incompleta. Con ello no se quiere decir que sea erróneo hablar de su origen en el Alto Duero y del puñal bidiscoidal como una importante pieza en el proceso de formación, sino que consideramos que se ha caído en la sobrevaloración de ambos factores, sobre todo del segundo, y en el olvido del resto de los pueblos de la Meseta Norte y en particular de su armamento, diferenciado del celtibérico e igualmente capaz de influir en el armamentarium romanorum.

\section{LA VARIABLE IGNORADA: EL PUÑAL DE FILOS CURVOS}

El puñal de filos curvos — conocido también como tipo La Osera y Villanueva de Teba es un arma muy poco conocida a día de hoy, incluso entre los círculos más especializados. Ya que, aunque las primeras piezas documentadas fueran halladas en las excavaciones de la necrópolis de La Osera en la década de los años treinta del pasado siglo, el ejemplar dado a conocer de la única de las zonas publicada (Cabré, Cabré y Molinero, 1950: 139-140 y 184185, lám. LXV-LXVI) no fue suficiente para otorgarle carta de naturaleza como un arma de

\footnotetext{
5 Para el problema terminológico De Pablo (2010: 364-365).
} 
la protohistoria meseteña a la altura del puñal Monte Bernorio o el bidiscoidal. Han sido investigaciones recientes las que han definido, no solo las características morfológicas del arma -Ruiz Vélez (2005) a partir únicamente de los ejemplares de la necrópolis de La Cascajera (Villanueva de Teba, Burgos)—, sino también su origen, dispersión geográfica y cronología (De Pablo, 2010), estableciéndose, ahora sí, como un nuevo tipo.

Este puñal, extendido por la cuenca media del río Duero y la zona del Alto Ebro, formó parte del armamento vacceo, autrigón o vettón durante los dos últimos siglos antes de la Era. $\mathrm{Su}$ origen, fechado a finales del siglo III o principios del II a.C., fue resultado de una profunda transformación de las piezas locales, a partir de las influencias de otras armas meseteñas.

El tipo presenta una gran uniformidad prácticamente en todos los elementos que lo componen: daga, vaina, tahalíes y broche de cinturón. Las dagas (fig. 1) muestran un único tipo de hoja, pistiliforme, con nervadura central, sección plana, finas acanaladuras en la superficie paralelas a los filos en número de 4 a 6 y hombros rectos, que suelen formar un ángulo de $90^{\circ}$ con el eje de la pieza. Éstas, fabricadas íntegramente en hierro y con una capa de magnetita que les da

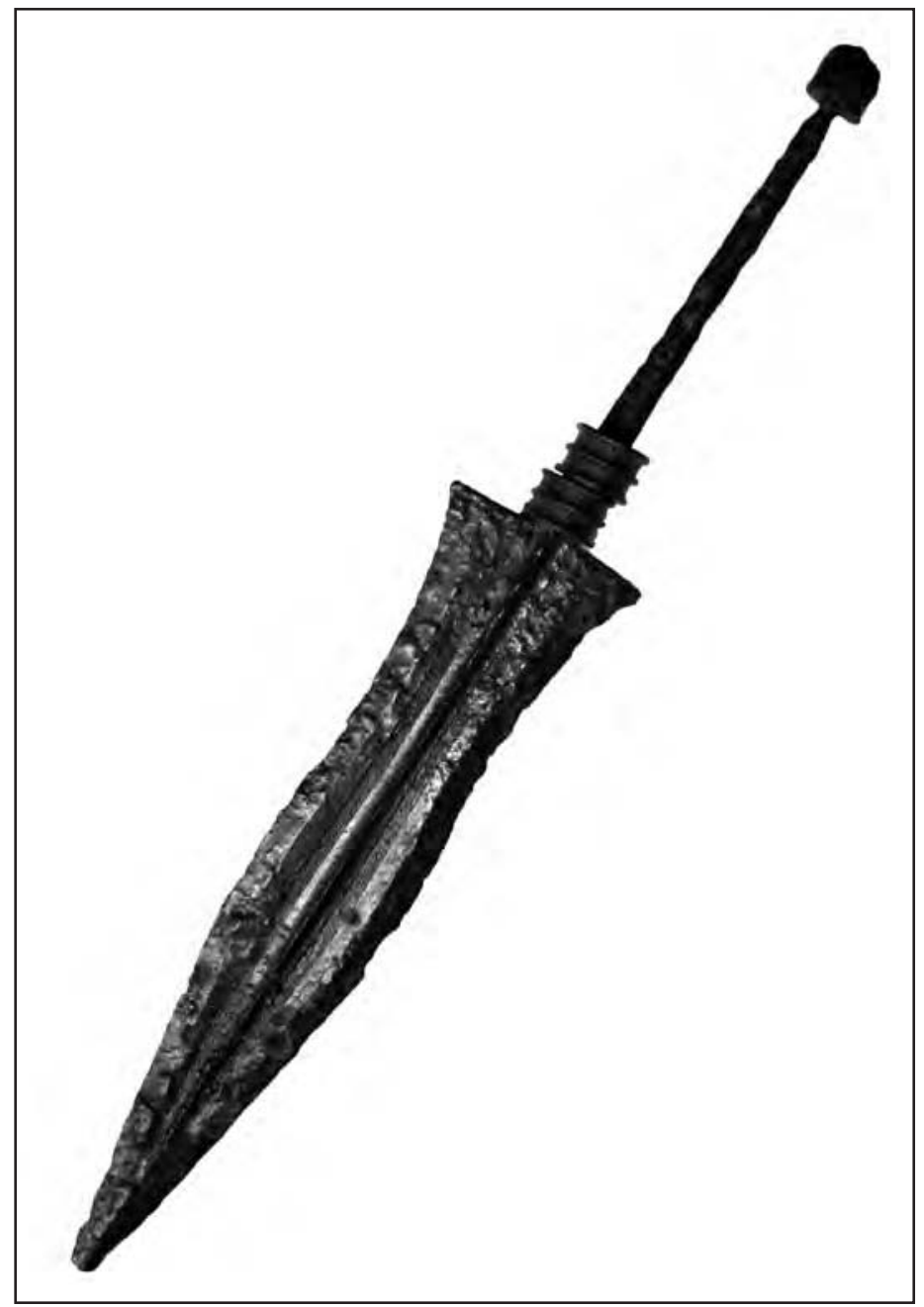

Figura 1. Puñal de filos curvos de la tumba 25 de la necrópolis de La Cascajera (Villanueva de Teba, Burgos) (fotografía de P. Molina Ortiz). 


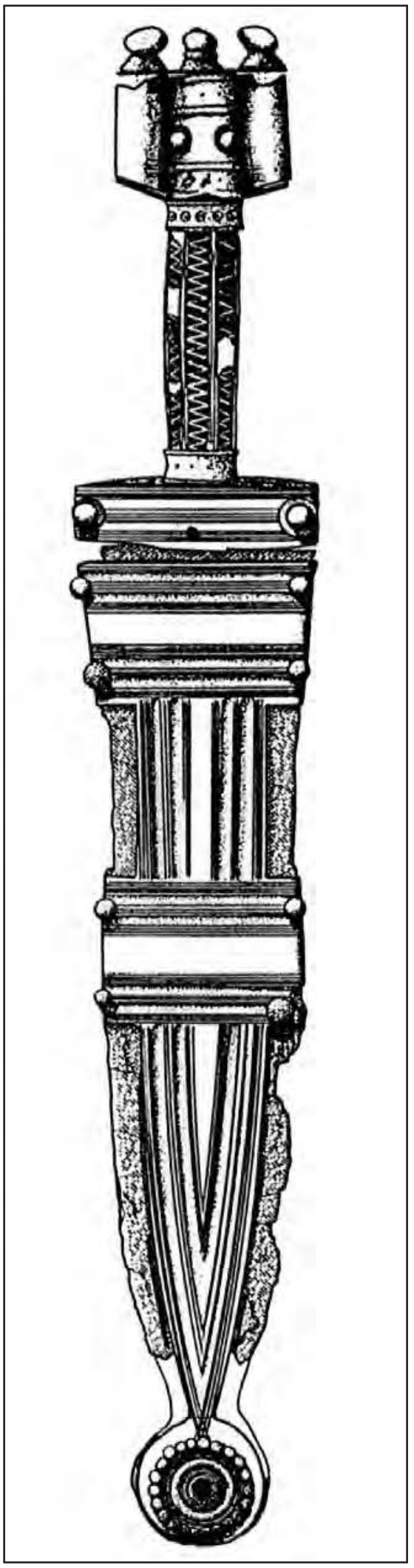

un intenso y brillante color negro, presentan unas medidas que varían entre los 17 y los $24 \mathrm{~cm}$ de longitud, sin incluir la espiga, y entre los 4 a $6 \mathrm{~cm}$ de anchura máxima. La espiga, solidaria a la hoja y de sección rectangular, soporta una empuñadura (fig. 2) formada por tres elementos - guarda, puño y pomo que remata en una virola de forma variable-, los cuales estuvieron hechos de material orgánico, y chapados ocasionalmente con láminas metálicas de bronce en el anverso y de hierro en el reverso. Las vainas (fig. 2), por su parte, están formadas por un armazón de cantoneras en hierro y dos láminas enterizas - de bronce la del anverso y de hierro la del reverso-, las cuales tienen dos ensanchamientos a modo de puentes - uno en la embocadura y el otro en la parte media-, donde se unen con las cantoneras mediante remaches, y un disco en la parte inferior, que forma junto con las cantoneras una contera discoidal hueca. En la parte trasera de la funda se coloca una pieza o elemento en S para la suspensión del puñal (Ruiz Vélez, 2005: fig. 5 y 8), la cual, con una inclinación de $45^{\circ}$ respecto al eje de la vaina, está rematada en sus extremos por dos anillas en las que engancharían dos pequeños tahalíes metálicos - a veces articulados- (fig. 4.2), que unirían el cinturón con la funda. Esta inclinación indica el lugar de suspensión de la vaina, colocada en la parte izquierda de la cintura del combatiente, y facilitaría el desenfunde del arma. Finalmente, el conjunto se completa con un gran broche de cinturón, de forma rectangular, perfil arqueado, rematado en un garfio en su extremo distal y chapado en bronce, al que suceden placas articuladas por bisagras, que en casos excepcionales llegaron a constituir un auténtico cinturón metálico.

Retomando lo dicho arriba sobre el origen del arma romana, vemos como este puñal muestra muchos de aquellos elementos que, ausentes en el bidiscoidal, se encuentran en el pugio. El montaje de la empuñadura sobre una espiga, los hombros de la hoja levantados formando ángulo recto respecto al eje de la pieza, las finas acanaladuras o estrías en la superficie de la hoja o unas hojas exclusivamente pistiliformes son algunas de esas características que ambos comparten (fig. 3). Sin embargo, son, sobre todo, las láminas enterizas que componen la vaina y forman una contera discoidal hueca y la suspensión del puñal en el cinturón median-

Figura 2. Puñal de filos curvos y vaina de la tumba 11 de la necrópolis de La Cascajera (Villanueva de Teba, Burgos) (Ruiz Vélez, 2005). 


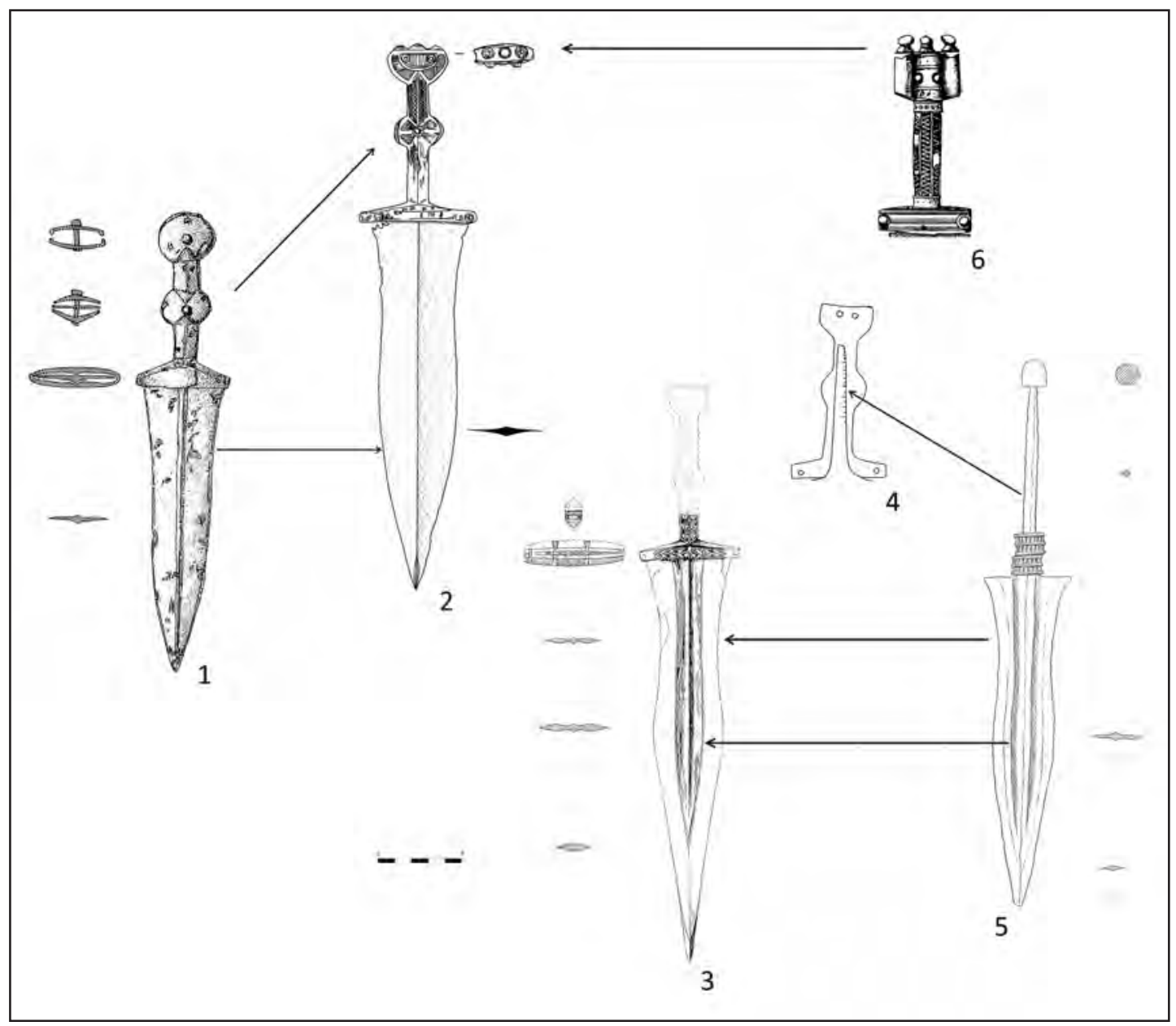

Figura 3. Influencias de los puñales indígenas sobre el pugio; 1. Puñal bidiscoidal de la tumba 512 de la necrópolis de Carratiermes (Montejo de Tiermes, Soria) (Argente, Díaz y Bescós, 2000); 2. Pugio de Allériot (Bonnamour, 1990); 3. Pugio de Leeuwen (Ypey, 1960-1961); 4. Estructura interna de la empuñadura del Pugio de Usk (Scott, 1985); 5. Puñal de filos curvos de la tumba 25 de la necrópolis de La Cascajera (dibujo de L. Pascual Repiso); 6. Empuñadura del puñal de filos curvos de la tumba 11 de La Cascajera (Ruiz Vélez, 2005).

te pequeños tahalíes metálicos en el lado izquierdo las características más exclusivas y, en nuestra opinión, las que ratifican la filiación entre el puñal de filos curvos y la daga romana (fig. 4). Las láminas de cubrición de la vaina del pugio muestran dos ensanchamientos -uno en la embocadura y el otro en la parte media- que actuarían como puentes y un disco rematando la contera (Bishop y Coulston, 2006: figs. 18.6 y 44.2-7), una estructura idéntica a la de las vainas de los puñales de filos curvos, aunque carente de las cantoneras en hierro que en algunas ocasiones parecen haber sido sustituidas por otros elementos orgánicos. Algo similar ocurre con los tahalíes metálicos, los cuales no solo permiten la suspensión del puñal en el lado izquierdo de la cintura del soldado, como ocurre con sus homólogos en los puñales de filos curvos, sino que también muestran una bisagra que articula la pieza. Aunque no podemos obviar que las vainas de los pugiones presentan algunas diferencias con las de los puñales de filos curvos, ya que el elemento en $\mathrm{S}$ ha desaparecido, trasladándose las anillas a los lados de 


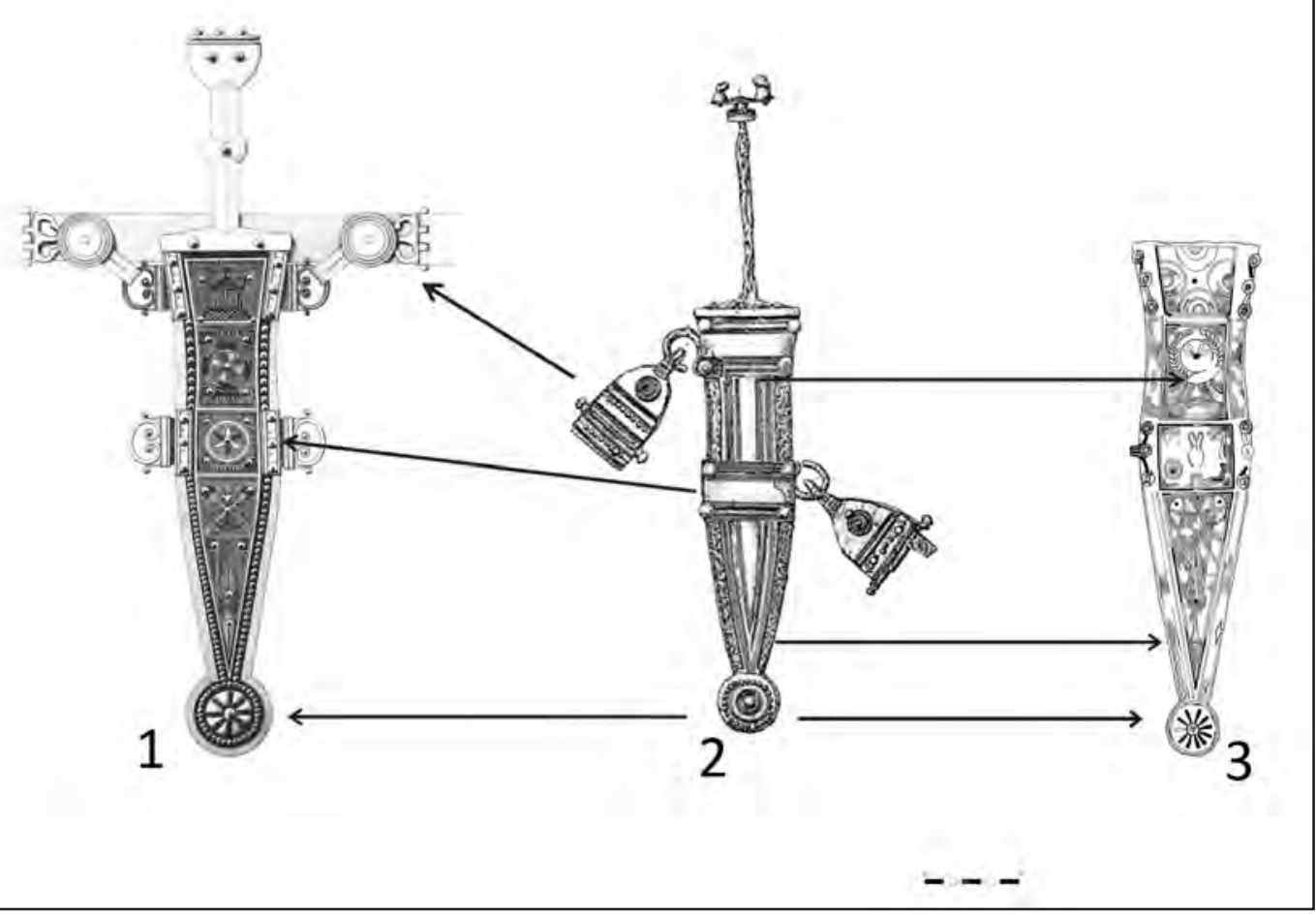

Figura 4. Influencias de la vaina del puñal de filos curvos sobre la vaina del puñal romano; 1. Reconstrucción del pugio de Velsen (Morel y Bosman, 1989); 2. Puñal y vaina de filos curvos de la tumba 27 de La Cascajera (Ruiz Vélez, 2005); Vaina de Allériot (Bonnamour y Fernoux, 1969).

los puentes y apareciendo ahora cuatro ${ }^{6}$ y no dos. Esta modificación en la vaina es posible por la existencia de las láminas enterizas que absorben la presión ejercida por el cinturón como antes lo hacía el elemento en $\mathrm{S}^{7}$, permitiendo además cualquier combinación entre las cuatro anillas, tanto paralela como diagonal, por lo que diríamos que se adopta la vaina con su sistema de suspensión pero se adapta a las necesidades de los legionarios romanos.

Redundaría en la relación pugio-puñal de filos curvos, que este último fue un arma que manejaron los pueblos prerromanos de la Meseta — vacceos, autrigones, vettones o cántabros- a los que se enfrentaría el ejército romano durante el siglo I a.C., centuria en la que localizamos ese hiato o laguna arqueológica. Esta relación, además, viene a ser reforzada por las diferentes piezas o elementos del puñal meseteño documentados en campamentos romanos, tal y como son la vaina de Nijmegen (Gerharlt-Witteveen y Hubrecht, 1990: fig. 15; Obmann, 2000: Taf.46.1), la placa de tahalí de Santa Mariana de Valdeolea (Fernández Vega y Bolado, 2009: 315-317 y 334, figs. 17 y 18) o la posible contera de puñal hallada en Dangstetten (Obmann, 2000: Taf. 27.2). Por lo tanto, y en otras palabras, esta arma está en el lugar adecuado en el momento preciso, y sería, como decíamos más arriba, pieza clave para conocer el origen del pugio.

${ }^{6}$ La finalidad de estas cuatro anillas podría estar orientada a que en un determinado momento los tahalíes metálicos se cambiaran de una a otra anilla; en batalla se utilizarían anillas a distinto nivel o lo que es lo mismo, una combinación diagonal, para que el puñal tuviera una inclinación de $45^{\circ}$, lo que facilitaría el desenfunde, mientras que para las marchas o vida cotidiana convendría tener el puñal totalmente vertical, utilizando las dos anillas superiores como muestran las estelas de los legionarios Firmus o Annaius Daverzus (Bishop y Coulston, 2006: fig. 150).

7 Ello explicaría además que la mayor parte de las láminas sean de hierro y no de bronce. 
Pero aun deja sin explicar algunos otros aspectos, como el pomo semicircular o en forma de D invertida, del que podemos puntualizar ciertas cosas al respecto. Es difícil rastrear cualquier relación entre los pomos semicirculares y los puñales de filos curvos, pues el pomo es el rasgo menos conocido de estas dagas y del que tan solo tenemos constancia de un ejemplar que lo conserve (Ruiz Vélez, 2005: 20-23, fig. 7, Lam. IV) entre el medio centenar de

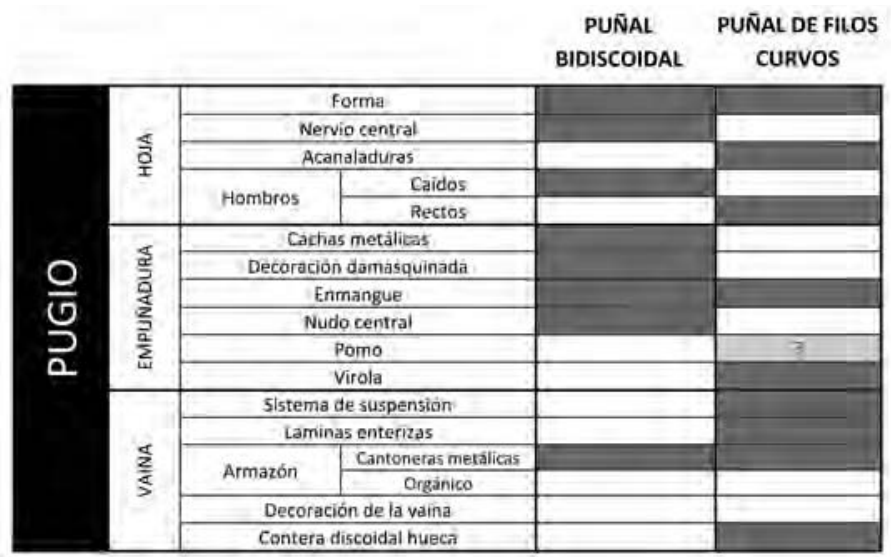

Figura 5. Elementos del puñal bidiscoidal y del puñal de filos curvos presentes en el pugio romano.

puñales conocidos, por lo que hay que suponer que estuvo hecho en la mayoría de los casos de material orgánico. Por el contrario, sí se conservan las virolas o botones que rematarían el pomo en los puñales de filos curvos, en número de 1 a 3 , y que nos recuerdan mucho a las que rematan los pomos de los pugiones de Utrecht (Ypey, 1960-1961: fig. 5), Oberammergau (Bishop y Coulston, 2006: pl. 1), Allériot

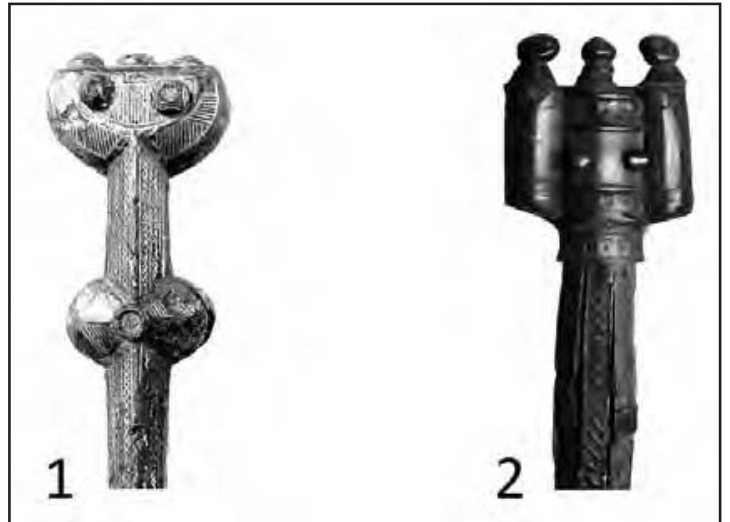

Figura 6. 1. Pomo del puñal Allériot (Bonnamour y Fernoux, 1969) y 2. Pomo del puñal de la tumba 11 de la Cascajera (fotografía de C. Santos Ozores) . (Bonnamour y Fernoux, 1969: figs. 1 y 4), o los restos del pomo de Velsen (Morel y Bosman, 1989: figs. 7 y 9A) (fig. 6). Asimismo, aunque puede resultar arriesgado, si acudimos a aquellos puñales que precedieron a los de filos curvos, los de enmangue en espiga (De Pablo, 2010: 378-385), vemos como algunos de ellos presentan pomos semicirculares o en $\mathrm{D}$ invertida, lo que nos podría dar una pista sobre la morfología de los puñales de filos curvos y el posible préstamo de estos últimos al pugio ${ }^{8}$.Incluso, al comparar el único pomo conservado en este tipo de puñal -el de la tumba 11 de La Cascajera- y el de los pugiones (fig. 6), observamos una nueva

8 Incluso viéndose la cronología de los puñales de enmangue en espiga, del S. III a.C. a comienzos del S. II a.C., se podría apuntar la posibilidad de que algunos de los ejemplares pervivieran hasta la conquista romana, a pesar de que se hubieran dejado de fabricar hacía tiempo. 
similitud, ya que los dos remaches del frontal del pomo están colocados en ambos de manera similar: flanqueando la espiga.

Visto todo esto y creyendo demostrada la filiación entre el puñal de filos curvos y el pugio, no consideramos deba hablarse de una simple evolución del bidiscoidal al pugio. Más bien, al contrario, entendemos la aparición del puñal romano como resultado de un largo y complejo proceso, que tendría lugar a lo largo del siglo I a.C., en el que aparecerán nuevas dagas vinculadas al aparato militar romano que recogerán las influencias de los dos tipos de puñales (figs. 3,4 y 5) que hemos estado viendo, el bidiscoidal, con el que llevaban en contacto varias décadas y había sido adoptado por algunos soldados y oficiales romanos en la Celtiberia, y el de filos curvos, arma característica de los pueblos del Duero Medio y que en menor medida también encontró cabida entre la panoplia de algunos legionarios romanos, como bien demuestra la vaina de este tipo de puñal hallada en Nijmegen (Gerharlt-Witteveen y Hubrecht, 1990: fig. 15; Obmann, 2000: Taf. 46.1). Durante este siglo I a.C. se vivirá una etapa de formación del arma en la que aparecerán diferentes modelos híbridos que mezclan elementos de los puñales autóctonos a la par que incorporan añadidos que reflejan las exigencias y necesidades de los soldados romanos. Estos puñales híbridos o experimentales, hallados fundamentalmente en el Medio Duero y la Cornisa Cantábrica —zona de actuación de las legiones romanas en Hispania en esos momentos-, se sucederán a lo largo de dicha centuria hasta que en un momento determinado un modelo se imponga con cierta claridad sobre los demás, siendo aceptado y entrando poco después a formar parte del armamento estandarizado romano y pasando a ser manufacturado en las fabricae castrenses. Aunque el pugio nunca llegará a mantener un estereotipismo tan acusado como aquellos puñales que influyeron en su origen.

Este proceso de formación del arma romana, al que hacíamos referencia líneas arriba, se vio favorecido por la compleja situación de la centuria. El fin de la conquista de la Celtiberia, el paso por el Duero Medio, con la conquista de las tierras vacceas, autrigonas o vettonas ${ }^{9}$, las Guerras Cántabras, y, sobre todo, las Guerras Sertorianas ${ }^{10}$ y Civiles provocaron el contacto continuo de las poblaciones del solar hispano con el ejército romano, contacto que se acrecentó con la incorporación de tropas indígenas en calidad de auxiliares.

A todo ello se nos abre una nueva pregunta, qué artesanos manufacturaron esos nuevos puñales, que se erigen como los prototipos o el germen de los futuros pugiones.

\section{RASTREANDO LAS MANOS DE LOS ARTESANOS}

Para finalizar examinaremos esos puñales que, fechados entre la segunda mitad del siglo I a.C. y principios del I d.C., se presentan como producciones intermedias, a medio camino entre los puñales indígenas y el pugio, y cuyo análisis tiene un doble objetivo, rastrear la autoría de estos puñales (qué artesanos hubo detrás de ellos) y ratificar la relación de estos con el puñal romano. Empresa para la que contamos no solo con nuevas armas hibridas o experimentales producidas para el ejército romano, sino también con puñales que, con una clara factura en la Celtiberia o en la cuenca central del Duero y alto Ebro, fueron puestos a punto y/o modificados a lo largo de su vida útil por esos artesanos vinculados al ejército romano. Aún así haremos una serie de apuntes a favor y en contra de estas dos posibilidades, con el fin de iniciar un debate al respecto.

En la actualidad, a partir de los datos arqueológicos que tenemos, fruto tanto de excavaciones modernas como de las practicadas durante la primera mitad del siglo XX, no podemos

\footnotetext{
9 Casi silenciado por las fuentes.

10 Momento en el que hubo incluso alianzas con ciudades vacceas, caso de Sertorio y Pallantia (Apiano BC, I, 112).
} 
asegurar si estas armas fueron hechas por artesanos oriundos de la zona o por el contrario manufacturadas por otros que, llegados a la Meseta de la mano del ejército romano, trabajaron en las oficinae armorum - y más adelante fabricae - campamentales y se vieron influidos por las producciones locales. Aún así haremos una serie de apuntes a favor y en contra de estas dos posibilidades, con el fin de iniciar un debate al respecto.

A favor de que fueran artesanos locales los que trabajaron para las legiones romanas, está el hecho de algunos puñales bidiscoidales vinculados con asentamientos romanos del Duero Medio muestran unas pequeñas laminitas en el canto, de plata o bronce, cuya decoración a base de triángulos enfrentados rellenos de perlitas es característica de los broches y tahalíes de los puñales de filos curvos; de la misma manera el que en algunos de los puñales bidiscoidales aparezcan unas finas acanaladuras paralelas a los filos, en número de cuatro o cinco, a cada lado del nervio central, muy parecidas a las acanaladuras que vemos en las hojas de los puñales de filos curvos.

Frente a esto, son varias las razones que nos hacen pensar que fueran manos foráneas las que fabricaron y modificaron estos puñales. Entre otras, al hilo de que lo hablábamos arriba, está el hecho de que esas mismas acanaladuras presentan un trazado muy irregular, lo que no es propio de un especialista que realice este tipo de incisiones a menudo; asimismo, el que el trazado de dichas acanaladuras levantara esa primera capa de magnetita, característica de las armas de la Protohistoria peninsular (Alonso y López, 2007) y que da mayor dureza y resistencia al arma, nos lleva a pensar que la persona que las hizo desconocía las técnicas de fabricación de los puñales de la Meseta, y no solo de los bidiscoidales sino también de los de filos curvos. Por otro lado, vemos que alguna vaina de nueva fabricación, como es el caso de una funda de la necrópolis de Eras del Bosque (Fernández Ibáñez, 2008: 133, 134 y 135, figs. 8,9 y 10), muestra una factura muy poco depurada, rematando la contera un disco martilleado, fruto de la unión de las dos cantoneras, y no el característico disco hueco de las vainas de los puñales de filos curvos, ni tampoco el aplique macizo que muestran muchas de las vainas de los bidiscoidales, asimismo la decoración tiene poco que ver con lo que muestran las fundas indígenas. A todo esto se une el hecho de que en las nuevas producciones se fusionen elementos que antes no se habían visto en un mismo arma, como por ejemplo anillas remachadas a los puentes de una vaina de láminas enterizas o empuñaduras de cachas de metal y nudo central dispuestas sobre enmangues en espiga. Por lo que cabe la posibilidad de que fueran artesanos foráneos los que fabricaron y/o modificaron estos puñales, aunque con profundas influencias de las producciones indígenas.

Aunque nos decantamos por la segunda opción, por creer la primera poco asentada, no deberíamos descartar una última posibilidad, y es el hecho de que un arma a lo largo de su vida útil pasara por las manos de más de un artesano que desconociera la técnica original de fabricación de dicho puñal y estuviera familiarizado, por el contrario, con la de otros. Ello explicaría que en algunos bidiscoidales aparezcan añadidos propios de los puñales de centro de la cuenca del Duero y otras intervenciones que serían impropias de alguien que conociera las técnicas de fabricación, no solo de los bidiscoidales, sino de cualquiera de las armas peninsulares. Lo que nos llevaría a pensar tanto en artesanos locales como romanos para las legiones durante el siglo I a. C.

A continuación veremos de manera pormenorizada los ejemplos más expresivos tanto, de puñales bidiscoidales con modificaciones en la Meseta ${ }^{11} \mathrm{y}$ de los puñales de filos curvos transformados, como de las nuevas producciones armamentísticas. El análisis de cada uno de ellos permite además afianzar la relación entre las dagas meseteñas y el puñal romano.

11 Aun habiendo sido localizados algunos en el limes germánico suponemos que esas alteraciones las sufrieron en territorio peninsular, ya que las legiones que estuvieron instaladas en los campamentos en los que se han hallado estas piezas anteriormente habían estado en Hispania, y particularmente en las Guerras Cántabras. 


\section{BIDISCOIDALES MODIFICADOS}

En primer lugar nos ocuparemos de los puñales bidiscoidales que, con una indudable factura celtibérica, sufrirán pequeñas transformaciones, ya sea por cuestiones funcionales, con el fin de mantenerlos activos, ya por estética. Este es el caso del puñal bidiscoidal de la necrópolis de Eras del Bosque en Palencia (Fernández Ibáñez, 2008: 97, figs. 2 y 3) (fig. 7), hoy custodiado en la colección Fontaneda, el cual con una clara factura celtibérica, constatada entre otras cosas por una empuñadura montada sobre lengüeta o un pomo discoidal, muestra en la superficie de la hoja unas finas acanaladuras paralelas a los filos de trazado irregular - por lo que las suponemos posteriores a la construcción del puñal一, en absoluto características de los modelos celtibéricos, y que nos recuerdan a las de algunos puñales de filos curvos, tanto por la forma como por el número. Por otro lado, este puñal también conserva en los costados de la punta huellas de afilado (Fernández Ibáñez, 2008: 97), por lo que éste arma se puso a punto en un momento determinado. Finalmente, el canto del pomo vemos que está decorado por una laminita de bronce decorada con un zigzag similar a los que vemos repetidamente en los broches de los puñales de filos curvos (Ruiz Vélez, 2005: 24-29), realmente escasos entre los ejemplares celtibéricos, y que curiosamente también se encuentran en el bidiscoidal de Monte Cildá (Alonso, 2004: 39, fig. 5), aunque esta vez en plata.

Un segundo ejemplar es la pieza de Titelberg (Vanden Berghe y Simkins, 2001), la cual, fechada entre el 30 y el 10 a.C., muestra una curiosa construcción, en la que podemos diferenciar, al menos, dos momentos: del primero son la hoja y la lengüeta, y del segundo, resultado de una modificación, la empuñadura rematada por tres virolas en su pomo. Aunque a día de hoy es difícil saber dónde se montó esa empuñadura, sí en cambio estamos en condiciones de asegurar que la hoja tiene una indudable fabricación celtibérica, algo que se percibe entre otras cosas en los hombros caídos de la misma, en los dos remaches que calan la guarda y la hoja y en que la empuñadura se monte sobre una lengüeta que además tiene un ensanchamiento central. La empuñadura por su parte, compuesta por dos cachas metálicas rematadas por un pomo en D invertida, presenta dos tipos de remaches, los primeros, de diámetro mayor $-4,5 / 5 \mathrm{~mm}$-, son los originales, mientras que los segundos, de tan solo $2 \mathrm{~mm}$ de diámetro, son aquellos que se colocaron con las nuevas cachas. Los segundos han ido interpretados por Vanden Berghe y Simkins (2001), por tener una cabeza semiesférica al exterior, como ornamentales; opinión que no solo no compartimos sino que creemos que son remaches totalmente funcionales, al estilo de los de cabeza semiesférica que se colocan en los puñales de filos curvos, cumpliendo una doble función: la de fijar las cachas a la lengüeta y la de embellecer el puñal. Asimismo, las tres virolas o botones que rematan el pomo, igualmente producto de ese segundo momento, recuerdan mucho a aquellas que rematan los de los puñales de filos curvos. Ello lleva a suponer que esta pieza, en su origen un bidiscoidal, pudo ser modificada por especialistas al servicio de Roma influenciados por las producciones meseteñas - los puñales de filos curvos-.

En esta misma línea está el puñal de Oberaden (Helmig, 1990: fig. 3c; Bishop y Coulston, 2006: fig. 42.1) que, manufacturado en la Celtiberia, presenta, al igual que el ejemplar de Eras del Bosque, cinco finas acanaladuras en la superficie de la hoja paralelas a los filos. Esto se pudo deber a que en un momento indeterminado, mucho después de la forja, su propietario decidiera, ya sea por estética o por creer que podían hacer el arma más eficaz, realizar esas acanaladuras mediante unas incisiones, las cuales levantaron la capa de magnetita, mucho más resistente dejando a la vista el hierro que forma el grueso de la hoja. No es de extrañar el hallazgo de un ejemplar como este en el campamento de Oberaden localizado en el limes germánico — que fue ocupado por tropas romanas entre el 11 y el 7 a.C. y en el que también se han documentado otros materiales llegados de Hispania, caso de las monedas estudiadas 


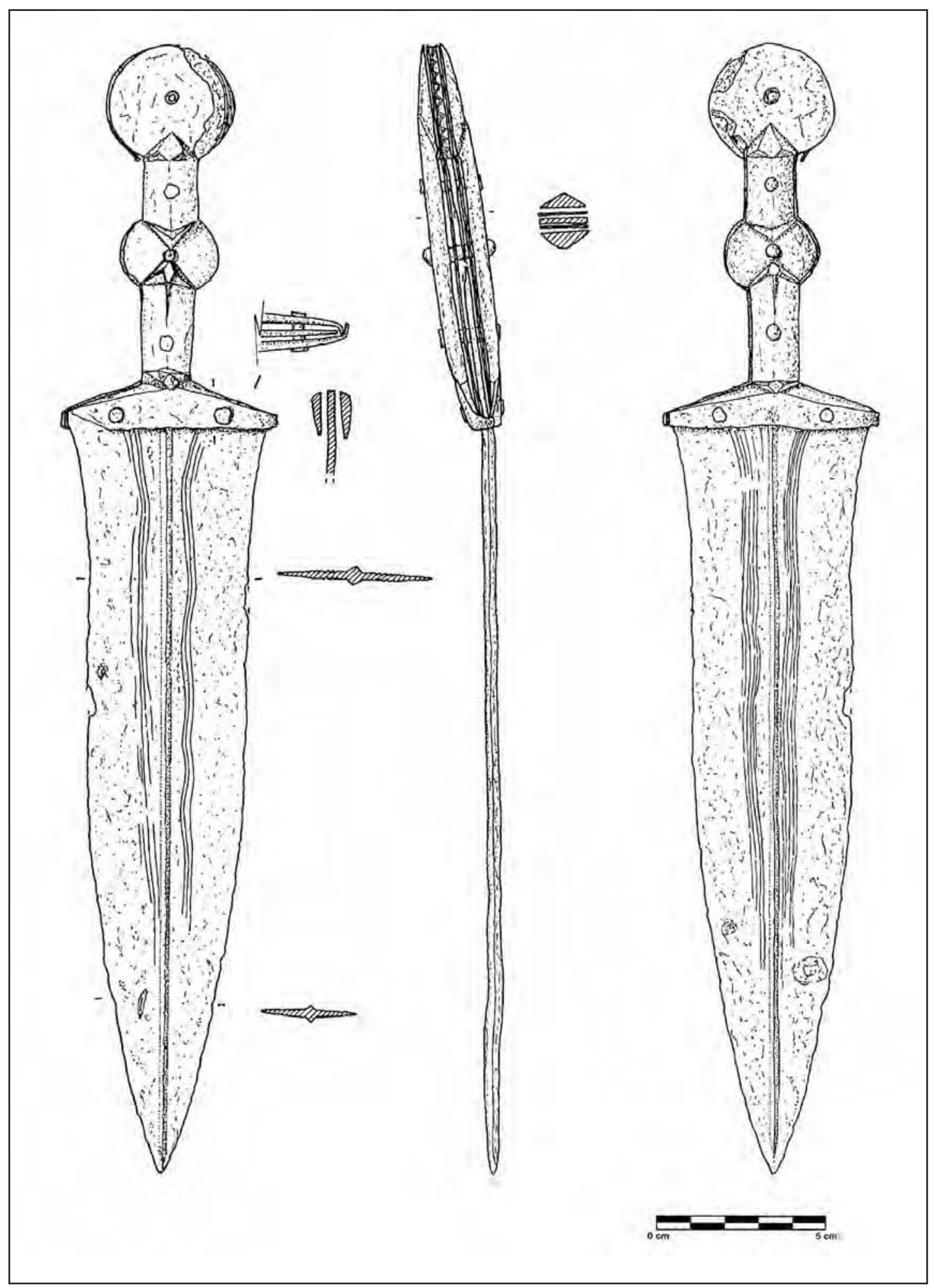

Figura 7. Daga bidiscoidal de Eras del Bosque (Fernández Ibáñez, 2008). 
por García y Bellido (1996) - ya que allí se acantonaron las tropas de la Legio I Augusta, legión que intervino en las Guerras Cántabras y que fue una de las primeras en abandonar suelo hispano tras dicha contienda (Morillo, 2003: 27). Este mismo puñal, presenta, además, en el pomo una decoración incisa lineal de círculos concéntricos sobre la que se dispone un motivo radial de seis haces que van desde el centro hacia la periferia, decoración ésta similar, a la que muestra el puñal bidiscoidal de la tumba 1.387 de la Zona V de La Osera (Kavanagh, 2008: 46), con damasquinados de plata y oro en este último caso. Concluiríamos pues, que en esta pieza, fabricada en la Celtiberia, se realizaron transformaciones copiando de manera tosca la decoración de ejemplares bidiscoidales del área vettona y algún elemento de los puñales de filos curvos, como son las acanaladuras.

\section{Puñales DE FILOS CURVOS TRANSFORMAdOS}

Parecería extraño que no contáramos con algunos ejemplares del tipo de filos curvos que hubieran acabado en manos de soldados u oficiales del ejército romano y que tras un tiempo de uso fueran modificados o puestos a punto, como ocurrió con los bidiscoidales que hemos visto más arriba. A este respecto contamos con dos ejemplares, procedentes de la Submeseta Norte, que sufrieron modificaciones.

El primero de ellos es un ejemplar hallado en Palencia capital, aunque de contexto desconocido, y custodiado en el Museo Arqueológico Nacional de Madrid (Fernández Ibáñez, 2008: 105, fig. 26) (fig. 8). Se trata de la lámina del anverso de la vaina de un puñal de filos curvos, con tres remaches a los dos lados de los puentes o ensanchamientos, en vez de los uno o dos característicos de estas vainas, que sujetan, a su vez, dos laminillas bífidas de las que cuelgan las anillas de suspensión. Vemos cómo en una vaina de fabricación claramente indígena se ha eliminado el característico elemento en S para ser sustituido por las cuatro anillas, situadas a los laterales de los puentes, propias de las fundas romanas.

El segundo caso es un conjunto de piezas custodiado en el Museo de Berlín (Born, 1998: 31-33, figs. 11-15) y proveniente también de la Península Ibérica; compuesto por un puñal de hoja pistiliforme con empuñadura de cachas metálicas, nudo en el puño y pomo semicircular, un broche de cinturón al que se le unen mediante bisagras dos placas articuladas, dos pequeños tahalíes en hierro y una vaina de contera discoidal con un elemento en $\mathrm{S}$ en la parte trasera. Tanto la vaina, como el broche y los tahalíes presentan el mismo ornato a base de pequeñas chapitas de oro, con decoración de triángulos llenos de perlitas, encajadas en una base de hierro que constituye la parte útil de cada una de las piezas. Se trata indudablemente de un grupo de piezas de producción local, muy parecidas a un bello ejemplar hallado en la necrópolis de Palenzuela ${ }^{12}$. Sin embargo, encontramos en la daga una empuñadura cuya morfología es idéntica a la de los ejemplares romanos y en absoluto propia de los puñales de filos curvos, lo que hace que pensemos que en un momento dado se sustituyó la empuñadura originaria, compuesta por tres piezas independientes, por otra formada por dos cachas metálicas al estilo de las empuñaduras de los modelos romanos, que como sabemos habían imitado la estructura de los bidiscoidales, o bien se sustituyó el puñal entero (no podemos afinar más dado la poca definición de la hoja en las fotos del trabajo de Bonn (1998)).

12 Agradecemos al profesor Ricardo Martín Valls su amabilidad al permitirnos mencionar aquí esta pieza inédita. 


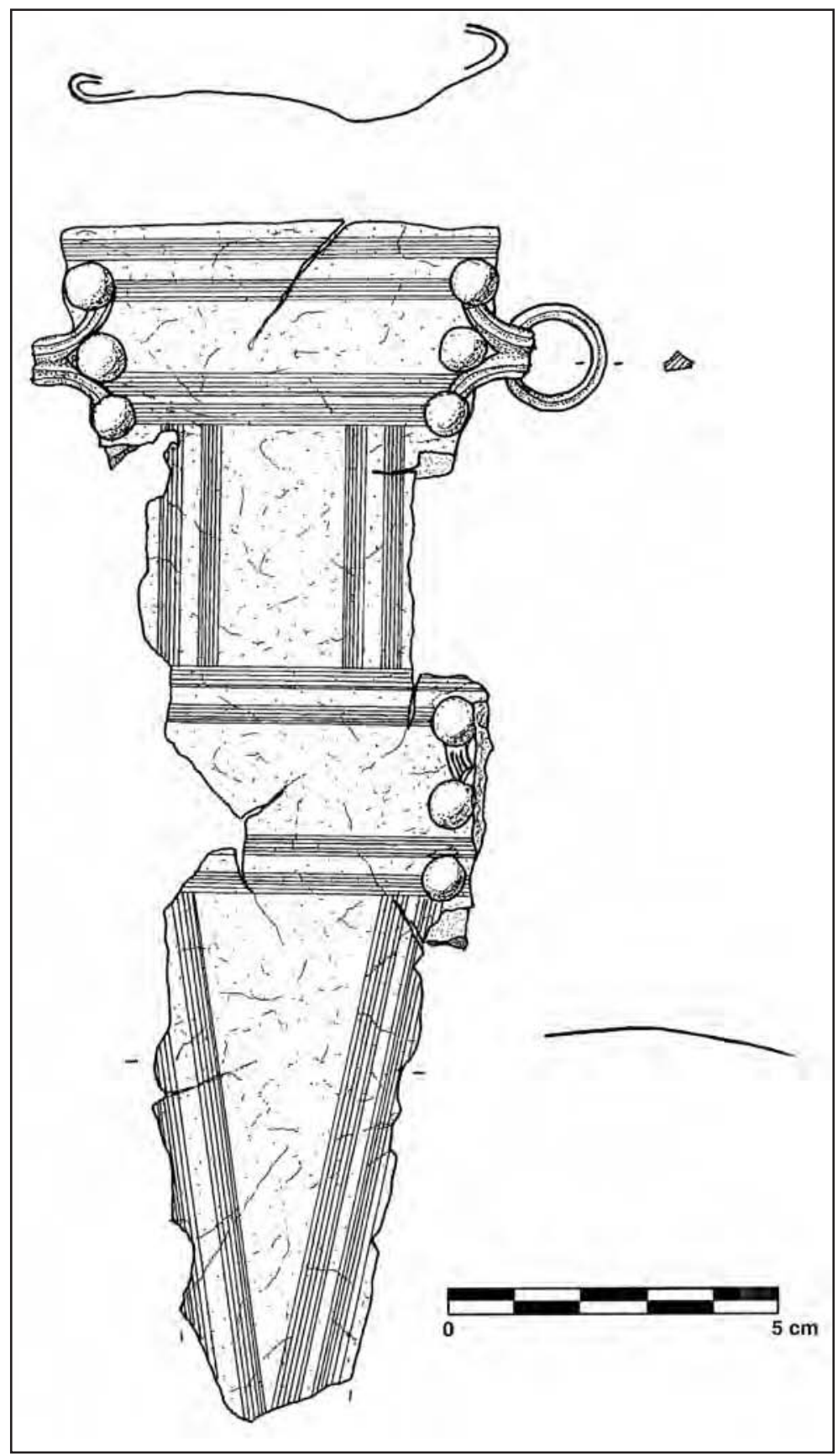

Figura 8. Vaina de un puñal de filos curvos modificada, necrópolis de Eras del Bosque (Palencia) (Fernández Ibáñez, 2008).

NUEVAS PRODUCCIONES PARA EL EJÉRCITO ROMANO

Por su parte, los puñales perdidos, deteriorados o inutilizados fueron sustituidos por otros de nueva factura, cuya producción, como ya hemos tenido ocasión de ver, estuvo influenciada 
por los dos tipos de puñales de la Meseta, dando lugar a ejemplares híbridos o experimentales. Estos puñales híbridos mostraban múltiples soluciones dado su carácter artesanal, sin embargo ya comenzaban a emerger y perfilarse las que, décadas más tarde, serían las características propias de los pugiones. Es por ello por lo que contemplamos a estas nuevas producciones como prototipos de pugio.

Estos puñales híbridos o experimentales han sido hallados fundamentalmente en el occidente meseteño, y excepcionalmente en el norte de Europa. Aunque son, sobretodo, dos ejemplares de la necrópolis palentina de Eras del Bosque los que mejor evidencian ese carácter experimental, por conservarse tanto el puñal como la vaina, conviene también tener en cuenta ahora un pequeño tahalí hallado en el campamento de la Legio IIII Macedónica en Herrera de Pisuerga.

El primero de ellos (Fernández Ibáñez, 2008: 133, 134 y 135, figs. 8, 9 y 10), muestra un aspecto exterior más cercano a los puñales bidiscoidales, aunque ya va introduciendo algunos elementos propios de los puñales de filos curvos como son los remaches de cabeza hemisférica, en los extremos de la guarda sin llegar a calar la hoja, y una virola esférica que remata un pomo, ya no discoidal como los modelos celtibéricos sino en forma de D invertida. La hoja, por su parte, muestra mayor parecido con las de los puñales del Alto Duero, puesto que siendo pistiliforme - característica que también comparte con los de filos curvos-, tiene un nervio central muy marcado que recorre toda la superficie, sin acanaladuras, desde la base hasta la punta, a lo que podemos añadir que los hombros de la pieza están ligeramente abatidos. Todo ello, unido a que la vaina presenta una decoración muy poco característica entre los ejemplares celtibéricos y una factura muy poco depurada, rematada en un disco plano resultado de la unión de las dos cantoneras mediante martilleado, y no con el característico disco hueco de las vainas de los puñales de filos curvos, ni con el aplique macizo que muestran muchas de las vainas de los bidiscoidales, hace que nos decantemos por pensar que este ejemplar no fue realizado por un artesano de la Meseta.

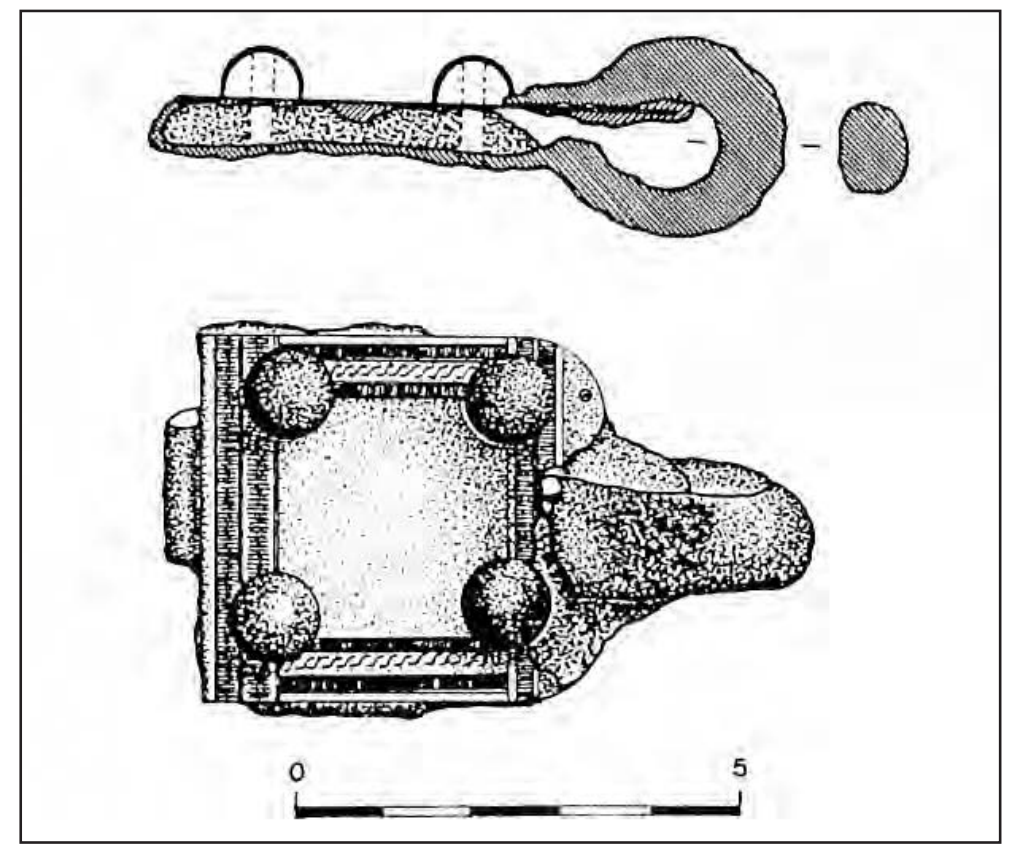

Figura 9. Placa de Tahalí hallada en el campamento de la Legio IIII Macedónica en Herrera de Pisuerga (Fernández Ibáñez, 1999). 
Por su parte, el segundo de los puñales de la necrópolis de Eras del Bosque, hoy conservado en la Colección Fontaneda (Cabré, 1931; Fernández Ibáñez, 2008: 144, fig. 19), presenta importantes analogías con los del limes germánico, situándose más cercano a ellos que su homólogo anteriormente descrito. Las influencias de los puñales indígenas en esta pieza son claras: morfología y construcción de la empuñadura y hoja pistiliforme con el nervio central marcado, influencia de los bidiscoidales; y vaina constituida por láminas enterizas- de bronce en el anverso y de hierro en el reverso - rematadas en disco, igualmente que una hoja pistiliforme por parte de los puñales de filos curvos. Aunque a la vez vemos añadidos claramente romanos ajenos a las manufacturas locales, como las cuatro anillas de la vaina fijadas a partir de cinco remaches, la barroca decoración de la vaina, o un pomo en forma de D invertida. Muestra nuevamente inequívoca de esta hibridación entre los dos tipos de puñales prerromanos que mantenemos, y que sirven de puente entre los modelos meseteños y el romano.

Finalmente terminamos con el tahalí (fig. 9) hallado en el campamento de la Legio IIII Macedónica en Herrera de Pisuerga publicado por Fernández Ibáñez (1999), con quien coincidimos en que se trata de una pieza con indudables semejanzas a los tahalíes indígenas, y concretamente con los tahalíes bisagrados de los puñales de filos curvos; sin embargo, no coincidimos en la reconstrucción del cinturón legionario que hace a partir de pequeñas placas articuladas unidas una a otra, sino que creemos que esta pieza tendría tan solo una plaquita articulada más, y que sería esta segunda placa la que uniría directamente con la correa de cuero del cinturón, tal y como ocurre en muchos ejemplares indígenas, así como en algunos pugiones como el de Velsen, y como muestran las estelas de los legionarios del limes germánico a que anteriormente hemos hecho referencia. Este pequeño tahalí sería pues una pieza puente entre los ostentosos tahalíes indígenas - con una misma composición estructural, con una base de hierro y una lámina de bronce, y con una decoración grabada y troquelada - y los sencillos tahalíes que suspenden los puñales romanos, como el de Kempten o el anteriormente citado de Velsen.

\section{A MODO DE CONCLUSIÓN}

A lo largo del artículo hemos ido perfilando una serie de razones que vienen a ratificar, si aún quedaba algún atisbo de duda, que el pugio romano posee un origen hispano en prácticamente todos sus elementos y que su génesis obedece a la fusión de las características estilísticas, morfológicas y estructurales de dos tipos de dagas de la protohistoria meseteña: los puñales bidiscoidales y los de filos curvos. El proceso de formación del puñal romano se iniciaría así en el Alto Duero, cuando las legiones romanas toman el puñal bidiscoidal como trofeo de guerra o botín; la posterior incursión ${ }^{13}$, ya en la primera centuria antes de la Era, a tierras vacceas, autrigonas o cántabras va a hacer que entren en contacto con el puñal de filos curvos, que influirá asimismo en las producciones romanas, dando pie a la creación una nueva arma, con rasgos de unos y otros, además de los añadidos romanos (figs. 3, 4 y 5).

La entrada en escena de una variable totalmente ignorada hasta hoy, hace que podamos dar un importante paso adelante en el conocimiento no solo del origen del pugio, sino también de sus raíces, cerrando algunas de las incógnitas que se habían planteado en los últimos años. Sin embargo, queda por resolver, pese a todo, quienes fueron los artífices de las diferentes innovaciones y, en definitiva, de los modelos puente ${ }^{14}$ entre los puñales indígenas y el pugio. Aunque

13 Aunque las fuentes clásicas recogen las noticias sobre algunas incursiones del ejército romano en el Duero Medio durante el siglo II a.C., diferenciamos estas acciones que las propias de conquista de la zona en la primera centuria antes de la Era.

14 Aquellos que hemos denominado prototipos de pugio. 
algo podemos suponer, ya que pese a que algún indicio apunta a una manufactura autóctona, la mayor parte induce a hablar de artesanos no indígenas en la fabricación de estos puñales durante el siglo I a.C. En el paso del ejercito romano por tierras del Duero podemos reconocer dos momentos claramente diferenciados: en primer lugar, la conquista de la Celtiberia, hasta finales del siglo II principios del siglo I a.C., momento en que los soldados de las legiones romanas se sirvieron de las producciones indígenas sustituyendo así sus armas gastadas o perdidas y añadiéndolas de manera no oficial a su panoplia dada la similitud entre las celtibéricas y romanas (Quesada, 2003: 188-193; 2006b: 164) —algo lógico teniendo en cuenta que cada ciudadano tenía que suministrase su propio armamento, costumbre que todavía seguía estilándose en estos momentos tal y como nos dice Polibio (VI, 22)—; y seguidamente, la conquista del resto de la Meseta y el noroeste peninsular, durante la segunda mitad del siglo I a.C., momento en que es fácil que hubieran funcionando algunas officinae armorum - luego fabricae- que, integradas por artesanos foráneos, manufacturaron nuevos modelos que imitaban las características de los puñales indígenas, solventando así las necesidades armamentísticas de las legiones que anteriormente habían tenido que resolver mediante la adopción de armas autóctonas. Entre estos dos periodos, en los que parece que hay un cambio en el abastecimiento de armamento y acceso a las armas por parte de los soldados romanos, está la lex militaris de C. Sempronio Graco, del 123 a.C., y, más adelante, la reforma de C. Mario en el 107 a.C., que supuso en palabras de Goldsworthy (2005: 46) la ruptura del lazo entre propiedad y servicio militar y la aparición del estado romano como distribuidor de armas. Ello explicaría, además de que haya un mayor número de puñales celtibéricos vinculados al aparato militar romano que puñales de filos curvos, las intervenciones en algunas dagas de producción local y la aparición en el siglo I a.C. de unos puñales híbridos que mezclan elementos de dos tipos de dagas indígenas pero realizados con técnicas de fabricación diferentes a las del mundo prerromano.

\section{BIBLIOGRAFÍA}

Alonso Gregorio, O. A. (2004): «Sobre el hallazgo de un puñal biglobular en Monte Cildá (Aguilar de Campoo, Palencia): la panoplia militar indígena al servicio de Roma» Sautuola, X: 35-46.

Alonso López, J. y López Sebastián, P. (2007): «Armas Negras en la Protohistoria de la Península Ibérica. Restauración y Caracterización Morfoestructural». Akobe, 8: 60-64.

Argente, J. L., Díaz, A. y Bescós, A. (2000): Tiermes V Carratiermes necrópolis celtibérica. Valladolid, Junta de Castilla y León, Consejería de Educación y Cultura (Memorias Arqueología en Castilla y León 9).

Bishop, M. C. y Coulston, J. C. N. (2006): Roman military equipment: from the Punic Wars to the Fall of Rome. Oxford, Oxbow.

Bogaers, J. E. y Ypey, J. (1962-1963): «Ein neuer römischer Dolch mit silbertauschierter und emailverzierter Scheide aus dem Legionslager Nijmegen». Berichten van de rijksdienstvoorhet Oudheidkundig Bodemonderzoek, 12-13: 87-98.

Bonnamour, L. (dir.) (1990): Du silex à la poudre. 4000 ans d'armement en Val de Saône. Catalogue de l’Exposition. Montagnac.

Bonnamour, L. y Fernoux, H. (1969): «Un poignard romain trouvé dans la Saone». Gallia, XXVII: 178-185.

Born, H. (1998): «Ziertechniken auf iberischen Eisenwaffen». En Müller-Karpe y Brandt (eds.) Studien zur Archäologie der Kelten, Römer und Germanen, Rahden, Westfallen: 23-42.

Cabré Aguiló, J., Cabré Morán, M. E. y Molinero, A., (1950): El Castro y la Necrópolis del Hierro Céltico de Chamartín de la Sierra (Ávila). Madrid: Ministerio de Educación Nacional, Comisaría de Excavaciones Arqueológicas. Acta Arqueológica Hispánica, V. 
Cabré de Morán, E. (1990): «Espadas y puñales de las necrópolis celtibéricas». En F. Burillo Mozota (coord.), II simposio sobre celtíberos. (1988, Daroca, Zaragoza). Zaragoza, Fundación Fernando el Católico: 205-224.

Connolly, P. (1997): «Pilum, Gladius and Pugio in the Late Republic». Journal of roman military equipment studies, 8: 41-57.

De Pablo Martínez, R. (2010): «Los Puñales de Filos Curvos en el Duero Medio y Alto Ebro. A propósito de los llamados tipo La Osera y Villanueva de Teba». En F. Romero y C. Sanz, De La Región Vaccea a la Arqueología Vaccea. Universidad de Valladolid - Centro de Estudios Vacceos «Federico Wattenberg» (Vaccea Monografías, 4): 363-396

Fernández Ibáñez, C. (1999): «Placa de tahalí para la suspensión de las dagas en el ejército romano: entre la República y el Imperio. A propósito de una hallazgo en el campamento de la Legio IIII Macedónica (Herrera de Pisuerga, Palencia, España)». En Estudios en Homenaje al Profesor Dr. García Guinea. Sautuola, VI: 335-345.

— (2008): «Dagas del ejército altoimperial en Hispania». Gladius, XXVIII: 87-176.

Fernández Vega, P. A. y Bolado del Castillo, R. (2011): «El recinto campamental romano de Santa Marina (Valdeolea, Cantabria): un posible escenario de las Guerras Cántabras. Resultados preliminares de la campaña de 2009». MUNIBE, 62: 303-327.

Feugère, M. (1993): Les armes des romains: de la République à l'Antiqué tardive. París: Edition Serrance.

Filloy Nieva, I. y Gil Zubillaga, G. (1997): «Las armas de las necrópolis celtibéricas de Carasta y La Hoya (Álava, España): Tipología de sus puñales y prototipos del pugio». Journal of roman military equipment studies, 8: 137-150.

García-Bellido, Ma . P. (1996): «Las monedas hispánicas de los campamentos del Lippe ¿Legio Prima (antes Augusta) en Oberaden?», Boreas, 19: 247-260.

García Sánchez, L. (2009): Interpretación metalográfica de piezas arqueológicas de aceros: Tecnologías de fabricación y posibles intervenciones posteriores. Tesis doctoral inédita, Madrid: Universidad Complutense de Madrid.

Gerharlt-Witteveen, A.M. y Hubrecht, A.V.M. (1990): «Survey of Swords and Daggers in the Provinciaal Museum G.M. Kam, Nijmegen». Journal of roman military equipment studies, 1: 99-107.

Goldsworthy, A. (2005): El Ejército Romano. Madrid, Ediciones Akal.

Helmig, G. (1990): «Hispaniensis Pugiunculus? - Technologische Aspekteund Anmerkungen zum Fund einer Militärdolchscheide aus Basel», Archäologie der Schweiz, 13: 158-164.

Kavanagh de Prado, E. (2008): «El puñal bidiscoidal peninsular: Tipología y relación con el puñal militar romano (pugio)». Gladius, XXVIII: 5-86.

Kavanagh de Prado, E. y Quesada Sanz, F. (2009): «Between Celtiberia and Rome. Daggers with bidiscoidal hilts: Current research and analysis of the construction of the sheaths», Limes XX. 20th International Congress of Roman Frontier Studies, 2006, León. Anejos de Gladius 13, Madrid, 2009: 339-350.

Luik, M. (2002): Die Funde Aus Den Römischen Lagern Um Numantia im Römisch-Germanische Zeltralmuseum. Mainz, Habelt.

Morales Hernández, F. (2009): «El cerco de Numancia: el cierre del Duero». Gladius, XXVIII: 71-92.

Morel, J. M. A. W. y Bosman, A. V. A. J. (1989): «An Early Roman Burial in Velsen I» Roman Military Equipment Conference, V, BAR 476: 167-191.

Morillo Cerdán, A. (2005): «Hispania en la estrategia militar del Alto Imperio: movimientos de tropas en el arco atlántico a través de los testimonios arqueológicos». En C. Fernández Ochoa y P. García Díaz (eds.), III Coloquio Internacional de Arqueología en Gijón: Unidad y diversidad en el Arco Atlántico en época romana (Gijón, 2003), BAR Int. Series 1371, Oxford: 19-33.

Obmann, J. (2000): Studien zu römanischen Dolchscheiden des 1. Jahrhunderts n.Chr. Rahden/Westf.

Quesada Sanz, F. (1997a): «¿Qué hay en un nombre? La Cuestión del Gladius Hispaniensis». Boletín de la Asociación Española de Amigos de la Arqueología, 37: 41-58.

- (1997b): El armamento ibérico. Estudio tipológico, geográfico, funcional, social y simbólico de las armas de la Cultura Ibérica (siglos VI-I a.C.). Montagnac, Éditions Monique Mergoil. Monographies instrumentum, 3. 
- (2003): «El legionario romano en época de las Guerras Púnicas: Formas de combate individual, táctica de pequeñas unidades e influencias hispanas». Espacio, Tiempo y Forma, Serie 11, Historia Antigua, 16: 163-196.

- (2006a): «Armamento indígena y romano republicano en Iberia (siglos III-I a.C.): Compatibilidad y abastecimiento de las legiones republicanas en campaña». En A. Morillo (ed.), Arqueología Militar Romana en Hispania. Producción y Abastecimiento en el Ámbito Militar. León: Universidad de León, Servicio de Publicaciones, Ayuntamiento de León: 75-96.

- (2006b): «Los celtíberos y la guerra: tácticas, cuerpos, efectivos y bajas. Un análisis a partir de la campaña del 153». En F. Burillo (coord.), Segeda y su contexto histórico. Entre Catón y Nobilior. Fundación Segeda - Centro de Estudios Celtibéricos. Diputación Provincial de Zaragoza. Mara (Zaragoza): 149-167

- (2007): «Hispania y el ejército romano republicano. Interacción y adopción de tipos metálicos». Sautuola, XII: 379-401.

Ruiz Vélez, I. (2005): «La panoplia guerrera de la necrópolis de Villanueva de Teba (Burgos)». Gladius, XXV: 5-82.

Ruiz Vélez, I. y Elorza Guinea, J. C. (1997): «Los puñales de la necrópolis «protohistórica» de Villanueva de Teba (Burgos)». Boletín de la Institución Fernán González, 215: 273-304.

Sandars, H. (1913): The Weapons of the Iberians. Oxford, University Press. Archaeologia 64.

Schüle, W. (1969): Die Meseta-Kulturen der Iberischen Halbinsel. Berlin, Walter de Gruyter, Madrider Forschungen, 3.

Schulten, A. (1914): Numantia I. Die Ergebnisse der Ausgrabungen 1905-1912. Die Keltiberer und Ihre Kriege Mit Rom. München.

Scott, I. R. (1985): «First century military daggers and the manufacture and supply of weapons for the roman army». En M.C. Bishop (ed.),The Production and Distribution of Roman Military Equipment, Proceedings of the Second Roman Military Equipment Research Seminar, B.A.R. Int. Series 275, Oxford, 160-213.

Vanden Berghe, L. (1996): «Some Roman military equipment of the first three centuries AD in Belgian museums», Journal of Roman Military Equipment Studies, 7: 59-96.

Vanden Berghe, L. y Simkins, M. (2001/2): «Construction and reconstruction of the Titelberg dagger», Journal of Roman Military Equipment Studies, 12/13: 75-84.

Ypey, J. (1960-1961): «Drei römische Dolche mit tauschierten Scheiden aus niederländischen Sammlungen» Berichten van de rijksdienstvoorhet Oudheidkundig Bodemonderzoek 10-11: 347-362.

Recibido: 22/09/2010

Aceptado: 02/08/2011 